\title{
Penanganan berbagai Tingkat Kelengketan pada Alat gelas di Laboratorium dari Pengaruh Basa kuat Larutan $\mathrm{NaOH}$ beserta Ujinya
}

\author{
Sri Harjanto ${ }^{a}$, Indra Gunawan ${ }^{b}$ \\ ${ }^{a}$ Laboratorium Biokimia Departemen Kimia, Fakultas Sains dan Matematika \\ Universitas Diponegoro, Semarang \\ Corresponding Author E-mail : sri.harjanto69@gmail.com \\ ${ }^{b}$ Laboratorium Bioteknologi Departemen Biologi Fakultas Sains dan Matematika \\ Universitas Diponegoro, Semarang \\ E-mail : indra_mikrobiologi@yahoo.com
}

\author{
Received: $2^{\text {nd }}$ December 2019; Revised: $18^{\text {th }}$ December 2019; Accepted: $19^{\text {th }}$ December 2019; \\ Available online: $20^{\text {th }}$ January 2020; Published regularly: January 2020
}

\begin{abstract}
As PLP (Educational Laboratory Institution) or other laboratory personnel for their daily work, they are very closely related to the tools and materials in the laboratory scope, and cannot be separated from laboratory equipment in the form of instruments or glassware. The problem here is that there are times when we encounter glassware in the scope of a laboratory whose faucet is closed or the faucet cannot be opened because it is sticky, and on average it is used after using $\mathrm{NaOH}$ base solution. That is why we are here to try to do a test to find out how much the stickiness of a device made from glass raw materials. By using variable various levels of concentration of NaOH solution with different time periods. As a decay the detergent solution is also used in various levels of concentration and heating. . From the data of the stickiness level test results using variable concentrations of NaOH solution and detergent solution will get the results that with the increasing concentration of $\mathrm{NaOH}$ solution, the stickiness will also be stronger. Likewise with the passage of time the longer the NaOH solution comes into contact with materials made of glass, the harder it will become and the stickiness will also be stronger so that it will be more difficult to be released. while on a strong adhesiveness will be more effective when using the immersion method at a temperature of 60-70 ${ }^{\circ} \mathrm{C}$.
\end{abstract}

Key Words : lid and sticky glass tool faucet, detergent solution, glassware

\begin{abstract}
Abstrak
Sebagai PLP (Pranata Laboratorium Pendidikan) ataupun tenaga laboratorium yg lain untuk kesehariannya dalam bekerja sangat berhubungan erat dengan alat dan bahan-bahan dilingkup laboratorium, dan tidak bisa terlepas dari alat alat laboratorium baik itu berupa instrument ataupun alat gelas. Yang menjadi masalah disini ada kalanya kita menjumpai peralatan gelas di lingkup laboratorium yang tutup atau krannya macet tidak bisa dibuka karena lengket, dan rata-rata disebabkan bekas dipakai menggunakan larutan basa NaOH. Oleh karena itulah tujuan kami disini mencoba mengadakan pengujian utk mengetahui seberapa besar kekuatan daya lengket dari suatu alat yg terbuat dari bahan baku gelas. Dg menggunakan variable berbagai macam tingkat konsentrasi dari larutan NaOH dengan jangka waktu yang berbeda-beda. Sebagai peluruhnya di gunakan larutan detergen juga dalam berbagai tingkat konsentrasi dan pemanasan. . Dari data hasil uji tingkat kelengketan tersebut yang menggunakan variable konsentrasi larutan $\mathrm{NaOH}$ dan larutan detergen akan didapatkan hasil bahwa dengan semakin bertambah besarnya konsentrasi larutan $\mathrm{NaOH}$ maka daya lengketnya juga akan semakin kuat. Demikian juga dengan berjalannya waktu semakin lama larutan $\mathrm{NaOH}$ bersentuhan dengan bahan yang terbuat dari gelas maka akan semakin keras dan daya
\end{abstract}

Copyright (C) 2020, JPLP, e ISSN 2654-251X 
lengketnyapun juga semakin kuat sehingga akan semakin sulit untuk dilepaskan Adapun cara mengatasinya dapat menggunakan 2 metode yaitu untuk skala tingkat kelengketannya rendah cukup dengan metode tetesan, sedang pada kelengketan yang kuat akan lebih efektif bila menggunakan metode perendaman pada suhu $60-70{ }^{\circ} \mathrm{C}$.

Kata Kunci : tutup dan kran alat gelas lengket, larutan detergen, alat gelas

\section{PENDAHULUAN}

Sebagai PLP (Pranata Laboratorium Pendidikan ) ataupun tenaga laboratorium yg lain untuk kesehariannya dalam bekerja sangat berhubungan erat dengan alat dan bahan-bahan dilingkup laboratorium dan tidak bisa terlepas dari alat alat laboratorium baik itu berupa instrument ataupun alat gelas.

Dari pengalaman yg ada selama ini dalam kita bekerja di laboratorium kadang kita menjumpai adanya alat gelas yang karena kurang bersih dalam mencuci dan disimpan dalam waktu yang relative lama, sehingga pada saat akan digunakan kembali di dapati tutup dari alat tersebut yg susah untuk dibuka atau stop kran yang susah untuk diputar / macet. Dan kejadian ini sering terjadi pada alat gelas yang habis dipakai dengan menggunakan larutan $\mathrm{NaOH}$, karena larutan ini mempunyai sifat alkalis atau basa kuat sehingga ada tingkat kecenderungan menempel kuat dan mengeras dengan bahan-bahan yang terbuat dari gelas.

Sifat larutan basa secara umum terasa licin , rasa pahit, bila dicek dengan kertas lakmus dari warna merah akan berubah menjadi biru, dapat menghantarkan arus listrik dan apabila dilarutkan kedalam air akan menghasilkan ion Hidroksi $\left(\mathrm{OH}^{-}\right)$.

Adapun kekuatan suatu basa dapat ditentukan dari kemampuannya untuk melepaskan ion hidroksida yang bermuatan negative ( ion $\mathrm{OH}^{-}$) ketika dilarutkan kedalam air. Semakin banyak ion $\mathrm{OH}^{-}$yang dilepaskan maka akan semakin kuat sifat basanya. Reaksi ionisasi basa kuat merupakan reaksi kesudahan karena senyawa basa yang ada dalam larutannya terion seluruhnya menjadi ion-ionnya.

Secara umum ionisasi basa kuat dapat dirumuskan sebagai berikut :

$$
\mathrm{M}[\mathrm{OH}]_{\mathrm{x}(\mathrm{aq})}-------------------\mathrm{M}_{(\mathrm{aq})}^{+}+\mathrm{x}^{\mathrm{OH}_{(a)}}
$$

Sedangkan kaca atau gelas merupakan materi bening dan transparan /tembus pandang yang biasanya dihasilkan dari campuran silicon atau bahan silicon dioksida $\left(\mathrm{SiO}_{2}\right)$ yang secara kimia sama dengan kwarsa ( biasanya dibuat dari pasir), suhu lelehnya sekitar $2000{ }^{\circ} \mathrm{C}$. Adapun jenis kaca yang sering digunakan adalah kaca soda kapur yang terbuat dari $75 \%$ silicon $\left(\mathrm{SiO}_{2}\right)$ ditambah $\mathrm{Na}_{2} \mathrm{O}, \mathrm{CaO}$ dan sedikit zat aditif lainnya . Di dalam ilmu pengetahuan istilah kaca didefinisikan dalam arti secara luas yaitu merupakan gabungan dari berbagai oksida anorganik yang tidak mudah menguap ,yang dihasilkan dari dekomposisi dan peleburan senyawa alkali dan alkali tanah, pasir, serta berbagai penyusun lainnya. Kaca ini mempunyai sifat yang khas antara lain : merupakan padatan amorf, berwujud padat tapi susunan atomatomnya seperti pada zat cair, tidak memiliki titik lebur yang pasti, mempunyai viscositas yang cukup tinggi, transparan, tahan terhadap bahan kimia kecuali HF, efektif sebagai isolator .

\section{BAHAN DAN METODE}

Alat : Pengukur kekuatan tekan, labu ukur, corong pisah, buret, pipet tetes ,penagas beker gelas, hotplate Bahan : larutan $\mathrm{NaOH} 0,01 \mathrm{M} ; \mathrm{NaOH} 0,1 \mathrm{M} ; \mathrm{NaOH} 1 \mathrm{M} ; \mathrm{NaOH} 2 \mathrm{M} ; \mathrm{NaOH} 4 \mathrm{M}$.

Larutan detergen $0 \%, 1 \%, 2 \%, 4 \%, 6 \%, 8 \%, 10 \%$.

Metode : dengan cara tetesan dan perendaman

Cara kerja :

Metode tetesan : Mula-mula disiapkan dulu larutan $\mathrm{NaOH}$ dengan berbagai tingkatan konsentrasi demikian juga untuk larutan detergennya, lakukan pembasahan tutup dan kran dengan larutan $\mathrm{NaOH}$ dengan konsentrasi sesuai variable demikian juga untuk jangka waktu pendiamannya, kemudian alat gelas dibersihkan dahulu terutama pada bagian kran atau tutup yang akan dilepas / macet, cek tingkat kelengketan 
dengan memutar kran atau menarik tutup yang macet secara pelan-pelan, kemudian tetesi di sela-sela rongga antara batang kran atau tutup dengan lubangnya , diamkan beberapa saat kemudian putar kran atau tarik tutup pelan-pelan, Jika masih lengket tetesi kembali dengan larutan detergen dg tingkat konsentrasi yang lebih pekat pada tempat yang sama kemudian diamkan sebentar dan diputar pelan-pelan, ulangi langkah tersebut diatas sampai kran atau tutup bisa terlepas.

Metode Perendaman :Mula-mula disiapkan dulu larutan $\mathrm{NaOH}$ dengan berbagai tingkat konsentrasi demikian juga untuk larutan detergennya, Lakukan pembasahan tutup dan kran dengan larutan $\mathrm{NaOH}$ dengan konsentrasi sesuai variable demikian juga untuk jangka waktu pendiamannya , Kemudian alat gelas dibersihkan dahulu terutama pada bagian kran atau tutup yang macet, cek tingkat kelengketan dengan memutar kran atau menarik tutup yang macet secara pelan-pelan, kemudian masukan alat gelas pada bagian yang macet tersebut kedalam penangas yang berisi larutan detergen , angkat sebentar sambil coba ditarik tutupnya atau diputar krannya pelan-pelan, kalo masih terasa keras direndam kembali sambil di panasi pada penangasnya sampai kira-kira suhu $60-70{ }^{\circ} \mathrm{C}$, Lakukan cara ini sampai tutup atau kran bisa terbuka

\section{HASIL DAN PEMBAHASAN}

Hasil uji Pelepasan tingkat kelengketan alat gelas dengan tekanan lepas 150 psi pada :

Tabel 1 Perendaman dengan Larutan $\mathrm{NaOH}$ selama 1 hari

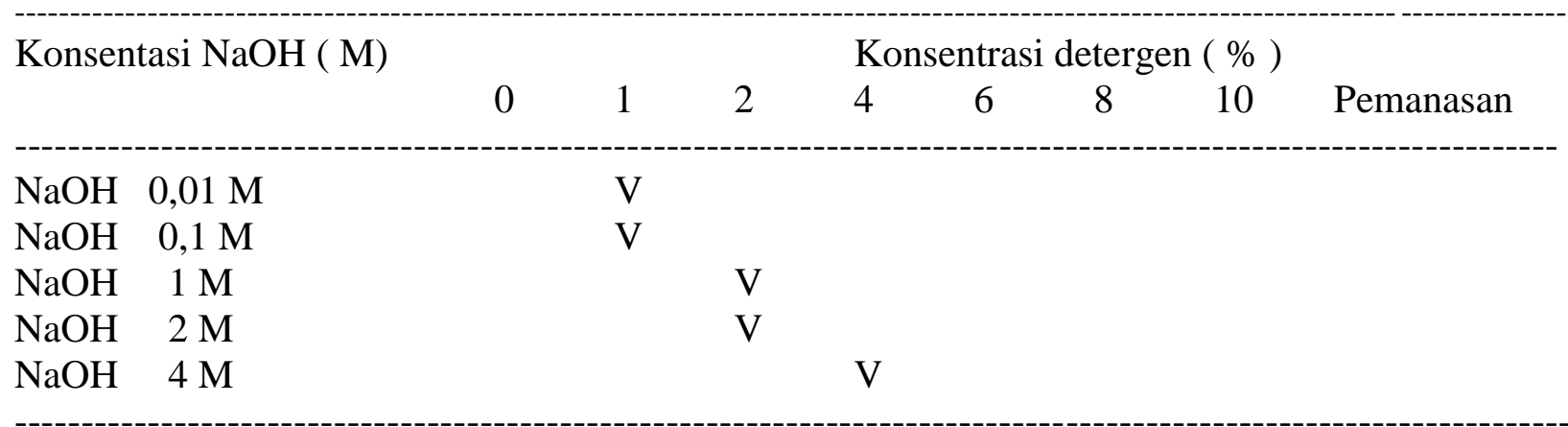

Tabel .2 Pendiaman selama 10 hari

\begin{tabular}{|c|c|c|c|c|c|c|c|c|}
\hline \multirow[t]{2}{*}{ Konsentasi $\mathrm{NaOH}$ ( M) } & \multicolumn{8}{|c|}{ Konsentrasi detergen ( $\%$ ) } \\
\hline & 0 & 1 & 2 & 4 & 6 & 8 & 10 & Pemanasan \\
\hline $\mathrm{NaOH} \quad 0,01 \mathrm{M}$ & & & $\mathrm{v}$ & & & & & \\
\hline $\mathrm{NaOH} \quad 0,1 \mathrm{M}$ & & & $\mathrm{v}$ & & & & & \\
\hline $\mathrm{NaOH} \quad 1 \mathrm{M}$ & & & & $\mathrm{v}$ & & & & \\
\hline $\mathrm{NaOH} \quad 2 \mathrm{M}$ & & & & $\mathrm{v}$ & & & & \\
\hline $\mathrm{NaOH} \quad 4 \mathrm{M}$ & & & & & $\mathrm{V}$ & & & \\
\hline
\end{tabular}


Tabel .3 Pendiaman selama 20 hari

\begin{tabular}{|c|c|c|c|c|c|c|c|c|}
\hline \multirow[t]{2}{*}{ Konsentasi $\mathrm{NaOH}$ ( M) } & \multicolumn{8}{|c|}{ Konsentrasi detergen ( $\%$ ) } \\
\hline & 0 & 1 & 2 & 4 & 6 & 8 & 10 & Pemanasan \\
\hline $\mathrm{NaOH} \quad 0,01 \mathrm{M}$ & & & & $\mathrm{v}$ & & & & \\
\hline $\mathrm{NaOH} \quad 0,1 \mathrm{M}$ & & & & $\mathrm{v}$ & & & & \\
\hline $\mathrm{NaOH} \quad 1 \mathrm{M}$ & & & & & $\mathrm{V}$ & & & \\
\hline $\mathrm{NaOH}$ & & & & & & & $\mathrm{v}$ & \\
\hline $\mathrm{NaOH}$ & & & & & & & $\mathrm{V}$ & \\
\hline
\end{tabular}

Tabel.4 Pendiaman selama 30 hari

\begin{tabular}{|c|c|c|c|c|c|c|c|c|c|}
\hline \multirow{2}{*}{\multicolumn{2}{|c|}{ Konsentasi $\mathrm{NaOH}$ ( M) }} & \multicolumn{8}{|c|}{ Konsentrasi detergen ( $\%$ ) } \\
\hline & & 0 & 1 & 2 & 4 & 6 & 8 & 10 & Pemanasan \\
\hline $\mathrm{NaOH}$ & $0,01 \mathrm{M}$ & & & & & $\mathrm{v}$ & & & \\
\hline $\mathrm{NaOH}$ & $0,1 \mathrm{M}$ & & & & & & $\mathrm{v}$ & & \\
\hline $\mathrm{NaOH}$ & $1 \mathrm{M}$ & & & & & & & V & \\
\hline $\mathrm{NaOH}$ & $2 \mathrm{M}$ & & & & & & & $\mathrm{v}$ & $\mathrm{v}$ \\
\hline $\mathrm{NaOH}$ & $4 \mathrm{M}$ & & & & & & & $\mathrm{v}$ & $\mathrm{v}$ \\
\hline
\end{tabular}

Keterangan $\mathrm{V}=$ kondisi kran atau tutup bisa terlepas

Pendiaman Selama 1 Hari

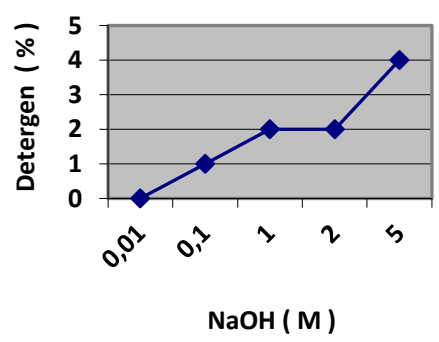

Pendiaman Selama 10 Hari

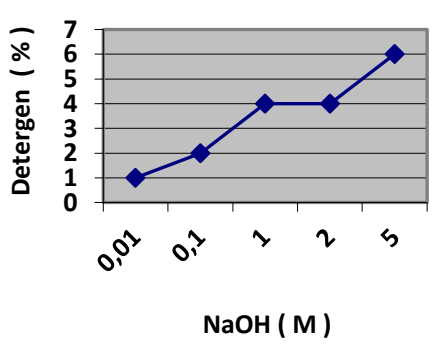

$\mathrm{NaOH}(\mathrm{M})$ $\longrightarrow$ Detergen yg digunakan

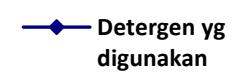
digunakan

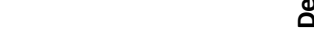


Pendiaman Selama 20 Hari

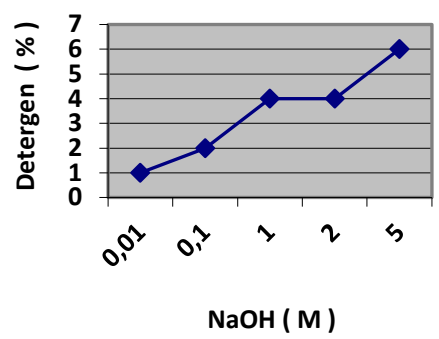

Pendiaman Selama 30 Hari
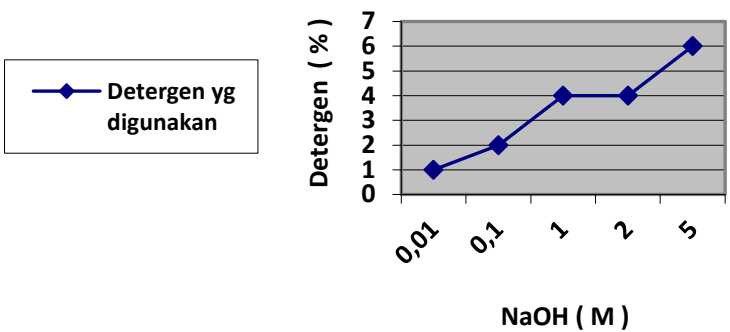
digunakan

Gambar 1. Grafik Pendiaman selama 1 hari, 10 hari, 20 hari dan 30 hari

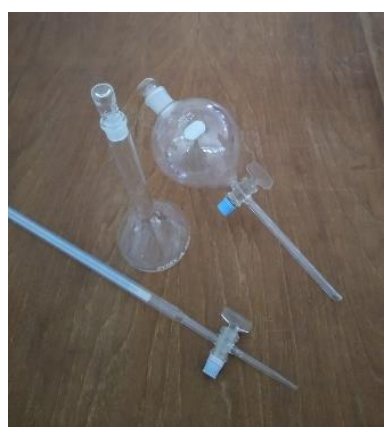

Gambar 2. Alat Gelas dg kran dan tutup kondisi macet

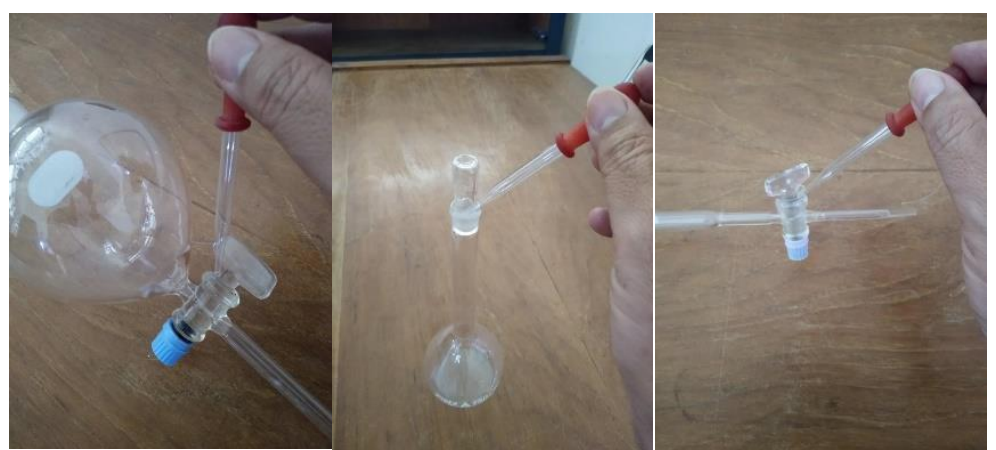

Gambar 3. Proses pelepasan tutup dan kran dengan metode tetesan 


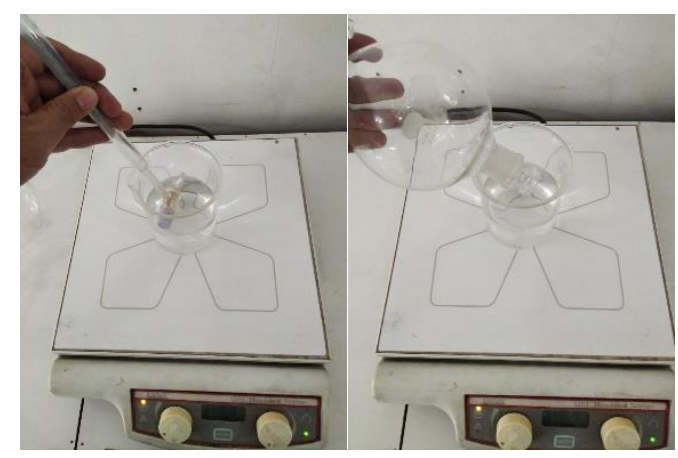

Gambar 4. Proses pelepasan tutup dan kran dengan metode perendaman

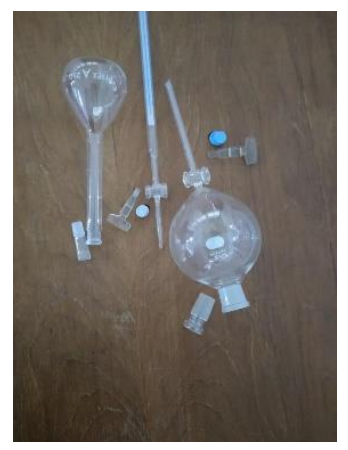

Gambar 5. Hasil dari pelepasan tutup dan kran

Dari hasil uji tingkat kelengketan tersebut di atas yang menggunakan variable konsentrasi larutan $\mathrm{NaOH}$ dan larutan detergen akan didapatkan hasil bahwa dengan semakin bertambah besarnya konsentrasi larutan $\mathrm{NaOH}$ maka daya lengketnya juga akan semakin kuat. Demikian juga dengan berjalannya waktu semakin lama larutan $\mathrm{NaOH}$ bersentuhan dengan bahan yang terbuat dari gelas maka akan semakin keras dan daya lengketnyapun juga semakin kuat sehingga akan semakin sulit untuk dilepaskan, kadang harus memerlukan suatu perlakuan khusus seperti dengan pemanasan. Dilihat dari hasil data pengujian pada Pendiaman 1 sampai dengan 10 hari bisa diatasi dengan metode tetesan saja sedangkan pada Pendiaman pada 20 sampai dengan 30 hari akan lebih efektif apabila dilakukan dengan metode perendaman dibantu pemanaan dengan suhu $60-70{ }^{\circ} \mathrm{C}$.

Dalam percobaan ini sebagai peluruh reaksi kami menggunakan larutan detergen karena mempunyai sifat basa ( alkalis ) dan licin, sehingga dengan sifat tersebut diharapkan bias membantu untuk melepaskan bagian tutup atau kran. Selain itu karena alat yang terbuat dari bahan baku gelas akan mudah rusak oleh lelehan alkali atau alkali karbonat pada $\mathrm{pH}$ kisaran 10 . Sedang dengan adanya bantuan pemanasan diharapkan bisa ada peregangan diantara kedua permukaan tutup ,kran dengan alat gelasnya sehingga akan mempermudah masuknya larutan detergen ke bagian celah yang lengket.

Ini semua sering terjadi pada saat setelah selesai Praktikum atau Tugas Akhir dari mahasiswa dengan alat gelas yang dalam kegiatannya menggunakan larutan $\mathrm{NaOH}$,sedang dalam mencuci atau membilasnya kurang bersih hingga tidak memperhatikan akibatnya, dan baru tahu setelah akan dipakai kembali tahutahu kran atau tutup dari alat gelas tersebut susah untuk dibuka / macet. Disini kami mengadakan uji tingkat kelengketan dengan maksud untuk membantu temen-temen yang dalam kegiatan sehari-harinya berkecimpung dilingkup laboratorium yang berhubungan dengan alat gelas dan larutan Basa kuat seperti $\mathrm{NaOH}$, mudah-mudahan hasil pengujian ini bisa bermanfaat. 
Dalam hal ini sebagai sampel uji coba kami menggunakan buret dengan krannya, labu ukur beserta tutupnya juga corong pisah beserta tutup dan krannya.

Dalam hal ini disarankan setelah pemakaian alat gelas diharapkan sebelum disimpan dicuci terlebih dahulu sampai bersih untuk menghindari kelengketan pada alat gelas.

\section{KESIMPULAN}

Dilihat dari hasil uji coba yang kami lakukan dalam usaha untuk mengatasi masalah di lingkup laboratorium khususnya yang berhubungan dengan hal kelengketan pada alat gelas atau kemacetan tutup , kran dari pengaruh larutan basa kuat $\mathrm{NaOH}$ bisa diatasi dengan menggunakan larutan detergen. Dari data hasil uji tingkat kelengketan tersebut yang menggunakan variable konsentrasi larutan $\mathrm{NaOH}$ dan larutan detergen akan didapatkan hasil bahwa dengan semakin bertambah besarnya konsentrasi larutan $\mathrm{NaOH}$ maka daya lengketnya juga akan semakin kuat. Demikian juga dengan berjalannya waktu semakin lama larutan $\mathrm{NaOH}$ bersentuhan dengan bahan yang terbuat dari gelas maka akan semakin keras dan daya lengketnyapun juga semakin kuat sehingga akan semakin sulit untuk dilepaskan Adapun cara mengatasinya dapat menggunakan dua metode yaitu untuk skala tingkat kelengketannya rendah cukup dengan metode tetesan , sedang pada kelengketan yang kuat akan lebih efektif bila menggunakan metode perendaman pada suhu 60 $-70 \circ \mathrm{C}$.

\section{DAFTAR PUSTAKA}

Harjadi, W.1990. Ilmu Kimia Analitik Dasar. Gramedia. Jakarta . 40-44

Bassett. J. et al 1994. Buku Ajar Vogel : Kimia Analisis Kwantitatif Anorganik. Kedokteran . EGC. Jakarta . 31- 37

Keenan, Charles W. et al 1991. Ilmu Kimia Untuk Universitas. Erlangga. Jakarta. 18,19

Day,R.A.,dan A.L. Underwood. 2002. Analisa Kimia Kwantitatif. Erlangga, Jakarta. 47,48

Sumardjo. 2006. Pengantar Kimia. Kedokteran EGC. Jakarta

Byan Technology Indonesia. 2011. Pengolahan Pasir Silika. http:// www. Byantech.com/ kategori pabrik/ pengolahan pasir silica.

Feihu D., Jingsheng L.,Xiaoxia L.,Zhang Z. 2010. Improvement of Iron Removal Silica Send Using Ultrasound Assisted Oxalid Acid. Ultrasonics Sonochemistry. 58-70 